\title{
Culture and Communication: Effects of Cultural Values and Source Credibility in a Multicultural SOCIETY, Nigeria
}

\author{
Kamaldin Abdulsalam Babatunde \\ University of Malaya \\ babsalam7@gmail.com \\ Siti Ezaleila Mustafa \\ University of Malaya \\ ezaleila@um.edu.my
}

\begin{abstract}
Coming from a psychological view of self concepts related theories: schemata and self construal, we investigated the effectiveness of celebrity endorsement in a multicultural society-African context. The study was to examine whether the celebrity endorsement strategy is effective in Africa culture as claimed in some studies. Focus group discussions were used in this study and their participants consist of different ethnic backgrounds in Nigeria. Findings indicate that celebrity endorsement is not effective in Nigeria cultural context and that African audience perceptions of source credibility are markedly different from the Western societies'. However, the study reveals that for celebrity endorsement effectiveness, cultural values play an important role. Recommendations for advertising managers and marketers are discussed as well as suggestions for future research.
\end{abstract}

Keywords: Source credibility, culture, Nigeria, celebrity endorsement, selfconstrual, Africa

\section{INTRODUCTION}

Different variables influence people's preferences, attitudes, and behaviours according to their cultural values. Scholars in different areas of disciplines: psychology, marketing, advertising, and communication have realized this and thus explored those variables effects on audience attitudes and behaviours in different societies. For example, scholars have investigated cultural differences across societies and its implication for their behaviour. They examined how people of different culture mentally perceive, use, and interpret cultural representations encoded in messages to frame their feelings and further their actions (Arnould \& Thompson, 2005; Hofstede, 1980; Hofstede, de Hilal, Malvezzi, Tanure, \& Vinken, 2010; Mick, 1992; Mick \& Buhl, 1992). 
This cultural value is processed mentally in relation to the receivers' frame of reference which signifies specific characteristics that differentiate a tribe from another and thus affect the receivers' interpretation and its effect on them (Dimofte, Forehand, \& Deshpandé, 2003; William B Gudykunst \& Ting-Toomey, 1988; Mick, 1992). The resultant effects of the process usually are expressed in terms of communicative and other forms of interaction among the people and their society (Žegarac, 2008). Moreover, studies have not only confirmed the existence of cultural variances among nations but also established cultural differences within a society as well (de Mooij \& Hostede, 2010; Gudykunst \& Ting-Toomey, 1988; Hofstede, 1980). Many researchers such as Gudykunst et al. (1996), Gudykunst \& Ting-Toomey (1988) and Mick (1992) acknowledge that these variances do influence comprehension and communication styles of different ethnic backgrounds which raise the imperative need to study cultural differences in relation to human behaviour.

Source effect is another variable which researchers believe impacts receivers' behaviour. The source effect concept is embodied in celebrity endorsement as the source of the message. This technique has received much attention especially among communication/advertising scholars and psychologists due to their belief in its effectiveness in behavioural change (Kamins, 1990; Kamins \& Gupta, 1994; Mishra, Roy, \& Bailey, 2015; Misra \& Beatty, 1990; Ohanian, 1991). Studies undertaken on the source effect and source credibility dimensions abound in Western societies and Asia with mixed results. However, Biswas, Hussain, and O'Donnell (2009) disagree on the most effective dimensions among source attractiveness, expertise, and trustworthiness. Nevertheless, studies have argued that celebrity endorsement strategy's effect is not automatic and therefore be used with caution (Biswas Hussain, \& O'Donnell, 2009; Reidenbach \& Pitts, 1986) because of other confounding factors in the society where it is being employed.

However, the influence of these variables on consumers has not been properly investigated in Africa. Although, some studies claimed that the celebrity endorsement strategy is effective in the African context but only fail to prove the required academic rigour of the study. And none of the studies has proved its external or internal validity. Moreover, none of the reviewed studies has considered African contextual factors in studying celebrity endorsement; especially in Nigeria where ethnic chauvinism exist. Since different ethnic groups possess attitudes, values, and norms specific to their culture (Cox, Lobel, \& McLeod, 1991), Dimofte et al. (2003) argue that 'contextual factors' deserve more consideration. Therefore, this study intends to investigate cultural variance and its influence on people's behaviour to understand persuasive communication's effect in a culturally diverse society. This is much important in a society such as Nigeria with a deep cultural cleavage. As understanding contextual factors' role would not only help in achieving effective communication but also in enhancing source credibility influence in Nigerian context.

To achieve this aim, the study theorized the concept of self-construal and self-schema to investigate persuasive communication effect on a multicultural public through the interplay between cultural values and source credibility. Put differently, to examine how and when people of different cultural backgrounds accept or resist persuasive messages from ethnic other than theirs based on source effect and source credibility. 


\section{CONTEXT OF THE STUDY}

Nigeria is the largest country in Africa with the estimated current population put at 197,724,142 (Worldometer, 2018). This population is made up of the largest aggregation ethnic groups in Africa- more than 250 ethnic tribes- subsumed under three major tribes: Hausa/Fulani 29\%, Igbo $18 \%$, and Yoruba $21 \%$ regarded as the most popular ones. These major tribes form $75 \%$ of the population; while the remaining percentage goes to other ethnics large enough to have a separate identity in the Nigerian census.

In addition, Nigeria maintains a multi-religious society with functional different sects. This diversity comes with different creeds and beliefs adding to the existing complexity of the cultural diversity of the people. Though Western culture has eaten deeply into some household, the traditional culture is still very much alive.

Ethnic diversity of the society reflects in the people's verbal and nonverbal communication styles. For instance, the southwest people communicate indirectly while the southerners do directly. Non-verbally, some ethnic-groups in Nigerians avoid eye contact when talking to people especially elders. This connotes a sign of respect-an act Western societies regard as lack of self-confidence in their cultures. Communication logic among Nigerians is contextual: searching for the wisdom behind certain behaviour and examining it in its context-not just taking it at a face value. However, few studies are available on Nigerian ethnic-groups communication patterns, and to this gap, this study contributes.

\section{LITERATURE REVIEW \\ Persuasive Communication}

People communicate when they believe the message is valuable to the relationships between the sender and the receiver (Falk \& Scholz, 2018) especially when it is a persuasive communication. By the world 'persuasive messages' we mean communication provided by an agent and directed to a specific public motivated by the intention of the sender to change the attitudes and behaviour of the receivers.

In every communication efforts, both the sender and the receiver of message engage in a transactional activity: come to the field with a different frame of references willing to negotiate and exchange. In this transaction, the agent's motive is to persuade the receivers while the receivers, in turn, are shielded with multiple barriers to avoid the messages or interpret them to their style. For the efficient negotiation, both the sender and receivers' frame of reference must overlap and the message must fit both values. Only in this instance that the desired effect, which is persuasion, is likely to occur when the exchange is based on subjective value (Falk \& Scholz, 2018).

Subjective value is a product of self-concept which aids individuals in the interpretation of objects and events based on their past experiences. This process allows messages of any genre to be read and perceived differently according to the social situation background of the receivers. Thus, the acceptance or resistance of the inducements lies first in "the social situations of their delivery" (Scott, 1994, p. 462), then in receivers' socio-cultural frame of reference. In addition, Mick and Buhl (1992) argue that people's life themes (lifestyles or individual differences) and life projects (meaning related to the self and extended self) affect their communication reception as well as their behaviour. Studies have shown that when the audiences are beamed with different symbols independent of their context, they interpret them 
to fit their lifestyle rather than feel a pressure to conform to specific cultural representations projected to them (Arnould \& Thompson, 2005; Mick \& Buhl, 1992). Therefore, advertising content independent of receivers' cultural values is challenging and may be refuted (AlbersMiller \& Gelb, 1996). Thus, persuasion effectiveness potential is high when the message fits into the receivers' life themes and projects of the receivers.

\section{Source Credibility Dimensions}

The use of celebrity endorsements as an advertising and marketing strategy to promote products, services or ideas has entrenched itself. The strategy has been in use for more than a century and a half (Erdogan, 1999; Kaikati, 1987). Marketers and advertising agencies have consistently employed celebrity endorsement strategy to attract more attention to their brands; this is either of the volition of the latter or on the request of the former. The use of the strategy is based on the belief that the target audience would place their trust in the celebrity as a source of the message for the brand. However, studies (de Mooij \& Hostede, 2010; Kamins \& Gupta, 1994; Martin-Santana \& Beerli-Palacio, 2013; Reidenbach \& Pitts, 1986; Silvera \& Austad, 2004; Tzoumakaa, Tsiotsoub, \& Siomkosa, 2014) show that different factors influence the effectiveness of celebrity endorsement in different societies.

Source credibility is the concept that is often used to measure celebrity effectiveness through the concepts of attractiveness, expertise, trustworthiness with their subsets dimensions (Gotlieb \& Sarel, 1991; Morimoto \& Ferle, 2008; Ohanian, 1991; Pornpitakpan', 2004; Roy, Jain, \& Rana, 2013; Yoon \& Kim, 2016; Yoon, Kim, \& Kim, 1998). Attractiveness dimension effect depends on physical attractiveness (Ohanian, 1991), and its subset is similarity, likeability, and familiarity (Biswas Hussain, \& O'Donnell, 2009). The rationale behind source attractiveness is that message receivers liking for the celebrity would beget similarity between them and the product.

Expert dimension projects the celebrity as an experienced and knowledgeable source who is skilled and qualified to give valid assertions (Erdogan, 1999; Ohanian, 1991), while trustworthiness is defined as the degree of confidence in and level of acceptance of the speaker and the message by the audience (Ohanian, 1991); the subsets of trustworthiness measurement are: honest, reliable and sincere.

Despite the wide acclaimed effectiveness of celebrity endorsement, no general consensus among scholars on which of the dimensions is most effective in influencing audience behaviour. Ohanian (1990) found perceived source expertise, among the dimensions, as the most effective compared to attractiveness and trustworthiness; while other scholars (Petty, Cacioppo, \& Goldman, 1981) found source attractiveness as more powerful in low involvement product than other dimensions.

Scholars have always used these dimensions to measure and prove the effectiveness of celebrity. The indication is that to prove the effectiveness of the celebrity strategy, the path of previous researchers must be trodden to validate the dimensions and understand audience perception of the variables. This is not the case in almost all the studies in Africa and that proves dearth of enough studies to prove its efficacy in Africa.

\section{Cross-Cultural Perspective}

Culture is an important factor that plays different roles in shaping people's behaviour and its investigation is an intense interest in communication studies (Ang, 1990). And the commensurate studies with the importance abound in the West and Asia. For example, Mick 
and Buhl (1992) argue that meaning of a message lies in the receivers' reception manner and interpretation because they interpret the message to fit their own world rather than conform to the message in itself. Thus, researchers contend that advertisement contents that consider audience cultural values are more persuasive than those that do not (Biswas Hussain, \& O'Donnell, 2009).

In the same vein, Cho, Kwon, Gentry, Jun, and Kropp (1999, p. 61) argue that "a lack of fit may result when cultural dimensions are borrowed from a cross-cultural theory developed with respect to a social domain far different from the advertising context". The implication is that a communication strategy must be tailored to the socio-cultural context of the people rather than a style fits all cultures.

Along this line, to unravel perception of celebrity dimensions and its effectiveness, a rigour investigation has to be through the audience's cultural lens and direct from the horse's mouth. Therefore, focus group discussion was selected which avail the researchers to feel their feelings and assess their other nonverbal cues as well.

\section{THEORETICAL UNDERPINNING}

The study is hinged on two psychological theories: self-schemata and self-construal since persuasion effectiveness is based on the individual self-concept in relation to other. The word 'other' encompasses: product, human, and message since people's reaction to 'other' is based on their experiences. Individual sub-consciously reacts to and retain messages that are consistent with their self-concept on the selectivity perceptions processes. These selection processes work in tandem with the theories of self-schemata and self-construal to select what they attend to and retain what is in consonant with their internal cognitive structure. Self-schema has been a useful theory when it comes to communication and information processing as related to the self (Bargh, 1982; Bower \& Gilligan, 1979; Lewicki, 1984; Lodge \& Hamill, 1986; Markus, 1977; Nishida, 1999; Rogers, Kuiper, \& Kirker, 1977).

Along the same line, Markus (1977) maintains that self-schemata "are cognitive generalizations about the self, derived from past experience, that organize and guide the processing of self-related information contained in the individual's social experiences" (p.64). Therefore, people use self-schema to interpret cognitive representations received in their social lives and react accordingly.

Similarly, self-construal is a psychological theory to understand the relationship of self to others. In other words, the representation of an individual self and its implications for cognition, affect, and behaviour (Markus \& Kitayama, 199) Researchers have adopted this theory and acknowledged that a culture promotes either of the self-independent or interdependent, or the dual. (Cross, Hardin, \& Gercek-Swing, 2011; Lalwani \& Shavitt, 2013; Singelis, 1994; Triandis, 1989)

\section{RESEARCH PROPOSITIONS}

Scholars have elucidated individuals' differences and socio-cultural factors influence on their dispositions (Albarracin \& Shavitt, 2018; Cantor, 1990; Falk \& Scholz, 2018). They argue that the value people assign to their actions or choices is subjective and that contextual factors: social norms, individual differences, and communicator's attributes are important factors 
(Falk \& Scholz, 2018) that affect message processing (Briley, Jr, \& EnL, 2014), shape thinking, (Lalwani \& Shavitt, 2013) and consequently influence persuasion.

This study, therefore, is aimed at investigating how these factors affect the behaviour of persuasive message receivers in Nigerian cultural context. In another word, what are the factors responsible for the effectiveness of persuasive message-celebrity advertisement in Nigeria cultural milieu?

However, Agbo and Ome (2017) found the existence of both independent and interdependent culture among the Igbo tribes in Eastern Nigeria in their study of happiness perception. This shows the existence of the two self-construal dimensions within a subculture among Nigerian cultures. Therefore, this study propose:

P1 That persuasive message reflecting other cultural values such as customs, religion, etc are more likely to influence receivers than messages that do not.

P2 That source credibility is likely to be more effective on the receivers of the message.

P3 That ethnicity is more likely to exert influence on message receivers than other factors.

\section{RESEARCH METHODOLOGY}

This is a qualitative study that adopted a focus group discussion (FGD) for data collection on views and opinions of different ethnic groups on the celebrity advertisement in which a tribe other than theirs was used. A semi-structured questions guide which reflects the research objectives for the discussion was formulated thematically based on the study's propositions.

The FGD moderator's guide was presented separately to two veteran scholars in media effect studies who effected some corrections on the initial guide and later certified the subsequent guide as a comprehensive one. Salient points raised by discussants were adopted and reported in the results section of this study using narrative method.

Two sessions of Focus group discussion were held in Lagos and Ilorin, Nigeria. Ten participants were invited initially but six participants formed the discussion group due others' inertia to research studies - Nigerian factor. The group consists of male and female discussants with age range from 25 to 45 years. They represent different ethnic groups and different work strata of the society. The eligibility criteria for participation were: (1) age 18 and above, (2) watch television at least three hours in a week, and (3) must have watched 3-5 celebrity endorsement advertisements. The two sessions took place between November 2017 and January 2018 in two different states: Lagos and Kwara.

The discussants were contacted personally in their houses and offices with an initial informal invitation. The participants were selected on a purposive sampling to enable equal representation of each major tribe in the society. Participation of the contacted discussants was on their choices and this reflected in the number of those that later acknowledged the invitation as noted above. Each session of the discussions was 1 hour 15 minutes long. The discussion guide for a moderator was prepared on a thematic format (Biswas Hussain, \& O'Donnell, 2009; Deliens, Deforche, De Bourdeaudhuij, \& Clarys, 2015) to facilitate the identification of the salient points as related to the study as well as for the results presentation. 
Participants were asked to discuss their opinions in this order: Effect of celebrity advertisement; Recall of advert and the spokesperson's tribal trait; Source credibility perception.

With the permission of the participants, the discussion was audio taped electronically and later transcribed to extract the relevant information for the study. The data were analyzed using a thematic narrative method. In addition to the audio recording of the discussion, the researcher who served as the moderator also made use of observations technique to decipher the discussants' body language and gestures which may support or contradict their utterances; as this silent communication enhances the research method and gives more clues to implicit information.

Prior to the discussion, again the researcher explained the objectives of the study to the participants. Each of the discussants then signed the consent form with a promise of confidentiality and anonymity of their identity.

\section{FINDINGS}

Participants demonstrated their understanding of persuasive communication and its purposes. A participant who had previously participated in child immunization campaign which is vehemently resisted by the northern people narrated the following story and explained the impact of the Emir (a title given to traditional ruler in the northern part) of the state on the people's behaviour before allowing the children to be immunized.

"I was a member in a campaign for child immunization in the north some years back. We tried to give immunization to children by going from house to house. Despite that we speak their language, Hausa and the presence of two indigenes among us; we were chased like a thief with offensive utterances. In spite of all the announcements made on local radio and television, the turn-out was poor. Whenever we visited them at home they either ignore your presence or shout at you. At long last we were able to immunize many children but not until the second round of the campaign when we took a picture with the Emir (Emir is the chieftaincy title given to the traditional rulers in the north akin to Oba in the southern part of Nigeria) holding a child to be immunized. Banners were made with a picture of the Emir. We carried these banners on the campaign vans and fliers to every house we visited."

This scenario shows the amount of influence culture and religion exert on people's behaviour. The word "Emir" in some part of the country connotes an authentic authority that is highly held in esteem in the north- a dominantly Muslims part of the country.

As an introductory step, the participants were asked to share their opinions generally on advertisement effects in which they have mixed views.

“...sometime I buy goods as a result though economic power was also a supporting motive then."

“...don't buy because of advertisement but on word of mouth- referral."

And subsequently, they were asked to reflect on telecommunication celebrity adverts they had watched and the resultant effects. Although, discussants acknowledge advertisements 
effect on the basis of what it has to offer not because of the spokesperson. While some of the discussants maintain that adverts effect depends on the situations: their states of mind and the contents (financial stance and the advertisement content).

"... reward is what influences people mostly in any advertisement."

Participants admitted that the most important thing is the benefits it offers them. This shows that reward of advertisement is the most important thing to receivers. They also opined that they would not patronize a telecommunication service unless it is up to their expectations no matter who the endorser is. Ambassador is another term coined for a celebrity that represents telecomm companies in most of their outing events.

"I will not buy a telecomm network service that does not cover my area or provides an epileptic service simply because a celebrity was used."

“... if a telecom company offers more mega-bite even without using a celebrity it pays-off ...."

This attitude reflects some social factors. First, some of the telecommunication companies do not have a full coverage of the country, especially in remote areas. Second, some telecommunication networks are better than others in terms of service consistency and coverage. Also, the unemployment epidemic in the country made them expect added value content from the telecom companies because people get small-scale business that can sustain them for a while through their adverts. Therefore, company that gives opportunity to the public to make money attracts more customers than the one that does not. The participants also lament that:

"...paying huge amount to a celebrity that is already rich to endorse its service is not a solution...."

This shows that the audiences are aware of the huge amount involved in hiring celebrity to endorse a product which may not yield the needed economic value. Rather, the participants prefer the companies to upgrade their services and engage in the empowerment program for their customers than the huge amount paid to celebrities.

\section{Source Ethnic Perception}

To examine the ethnicity effect of the celebrity on the audience, views and opinions show that the tribe of the celebrity does not exert influence on the audience.

“...I do not care who says what but I am concerned about the benefit of the message."

“... No one cares about the ethnic of the celebrity in advert endorsing a product that does not offer quality."

"Why would I use a product or patronize a service provider simply because a celebrity from my tribe endorsed it- who might not even be using it- that will not happen. The celebrity is doing a paid for job." 
Contrary to the first proposition (P1) that ethnicity is more likely to influence the audience because of pervasiveness of tribal chauvinism and study's theoretical framework. The theoretical framework assumption is that individuals would use past self social experiencesself schema-to regulate their relationships with the spokesperson on ethnicity basis; therefore, loyalty to ethnic spokesperson syndrome. However, participants do not give vent to ethnicity. This also shows that the interdependent self-construal which assumes that both self and others are not separate but are intertwined prevails in Nigerians (Singelis, 1994).

Nevertheless, worth mentioning here is the moderator's observation of the difficulty some participants faced while trying to recall name of a celebrity endorser whose tribe differs from theirs. This happens severally even after being reminded of the celebrity name by other participants. This may imply a partial effect of ethnicity or a mere slip of memory coincidence.

Whether this could occur across the board, the moderator jogged the participants' memory by mentioning telecommunication advertisement with celebrity's endorsement. Thereafter, the discussants were asked to name the celebrities involved in the adverts. The findings reveal that some could not remember the names of a celebrity from their own tribe as well as other tribes. At this juncture, a salient point was raised.

"... I think it would have been better if a general celebrity is used in those adverts; this may aid memories in recalling the celebrity's name and perhaps enhance celebrity endorsement success."

The word general celebrity here refers to a football star in the national team as noted by the participants.

"...Since everybody likes and watches football matches, using any of our national team football star is better."

All celebrities featured in telecomm adverts are film actors and actresses, and despite that people watch their indigenous home drama and are emotionally attached to it, yet hardly recall the celebrities in the adverts. So, the suggestion of football celebrity boils down to the fact that football in Nigeria knows no ethnicity when it comes to passion for the game; besides, it is the only uniting factor for the country.

\section{Source Credibility Perception}

Investigating celebrity credibility, we were deliberately careful not to mention or allude to any of the source credibility three dimensions or their subsets to the participants during the initial discussion; hopefully to hear them use consciously any of the source credibility's dimensions to describe the celebrity. As expected, some of the three traits dimensions were used willingly by the participants. Those that were used frequently are trust, honest, expert, attract, and like, while similar, skill, experience, dependable, and qualify were not mentioned.

Most of the discussants opined that the spokespersons in advertisements are not credible. They affirmed that the celebrities were hugely paid to advertise the product or service.

"These people are in business contract involving huge amount of money. Why would

I believe or trust them when I know what they are saying is not true." 
"... though they attract crowd to the advert..."

This validates previous studies that celebrity generates publicity for the endorsed brand. In other words the spokespersons possess the aura of attractiveness. The common word used among discussants was 'ability to pull crowd'- because of their long-standing popularity but that does not make them patronize the product not even among their fans.

Interestingly, "attractiveness" is viewed from an emotional perspective, not the physical attractiveness dimension contrary to other studies; though Erdogan (1999) argues that attractiveness does not only mean physical characteristics of the celebrity, it also includes traits such as intellectual skills, personalities, lifestyles, or other prowess. But the longstanding use of attractiveness dimension and commonly referred to in studies is a physical attribute of the celebrity.

As regard the "expertness" trait of the spokesperson, participants equate it with the celebrity acting personae - their professional domain. This is so because most of the discussed and dominant endorsers in Nigeria are film actors/actresses as mentioned above. From this view, discussants perceived the celebrities as:

"... not fit for the product endorsed rather, they are doing what they do best-acting a script."

The major belief among participants is that advertisers realized that film personalities are the best to use for their product because of the vast experiences they have garnered in acting, thus can display expertise with different personae. The celebrity expertise is not perceived as skilled and experienced person to give valid assertions; thus, this contradicts the basic tenet of the construct as well as past findings.

This finding contradicts results from the West and the supposedly existing results in Africa. Perception of source credibility dimensions for African's audience is markedly different from the Western society; therefore contradicts P2 that source credibility would influence receivers.

To illustrate celebrity congruence with target audience importance to achieve celebrity effectiveness, participants recalled a successful story which was corroborated by a staff of the company in the group. The participant that works with a company that produce sweets- "OK POP" admitted that actors are the best to consider when you think of using spokespersons but target public characteristics must be considered as well.

"When we were considering how to sell "OK POP" sweet to the market, we explored many strategies before the company finally concluded to use two popular comedian actors loved by children because of their childish short statures. The actors known as Aki and Popo were used and it was a great success."

Notably, celebrities' congruence with the target audience is a reason mentioned for selecting the two actors. This is also the case with the grandma who was fascinated by a telecom company's advertisement that featured an aged woman as illustrated below. 


\section{Religion and Other Socio-Cultural Value Effects}

In terms of celebrity ethnic and other socio-cultural values influence, the following advertisement scenario has mixed outcome effects. The city of Ilorin is regarded as a Muslim dominant community where religion is ahead of every other thing. An Ilorin son, "core indigene" (a word used to qualify members of a dominating tribe in that state) was engaged in a campaign to sell liquor to the state. This campaign was seen as an attack and insult on the culture and religion of people of Ilorin and their integrity as well. A counterattack campaign was launched immediately to rebut the advertisement claim and redeem the image of Ilorin city. The resistance was not only against the product but also the spokesperson was asked to drop the contract entirely or face the wrath of the community.

This scenario and the following supports the proposition, $\mathrm{P} 3$ that other cultural values other than ethnicity are more likely to affect the receivers' attitudes, though the effect in this instance is negative for ethnicity while it is cultural values positive. The prevailing cultural values here are the religion of the people and their culture against alcohol consumption. To prove the rigidity of the culture, a bill was passed into law in the house of assembly to expel liquor sellers from the city and extend the radius of beer-parlour to the city. This is now made public and promulgated in the State.

Another culturally coded advertisement that exerts influence was a grandmother who watched a celebrity telecom endorsement of "Mama Rainbow" and insisted on buying it:

My mother was on her bi-monthly routine one week visit to see her grandsons. On one of her rear occasion watching television with the children in the living room, she saw something of interest to her, her similitude.

A woman of her age (Mama Rainbow) was featured in an advert exchanging pleasantry with her son and enquiring about his family. Afterward, she went into (dishing out) invocations on his son and the whole family. The invocations took 15- 20 minutes before the son requested that she should stop as he has other things to attend to. She was making a phone call using a telecommunication network. The telecomm company got its hook into my mother; she insisted on buying the SIM card of the telecomm that can give her opportunity to have long conversation with her grandsons!

The above examples illustrate the spokesperson's cultural background influence on receivers of persuasive message.

\section{CONCLUSION}

From the results of the study, we found that celebrity endorsement is not effective in the Nigerian context because it fails to yield the required results. This finding contradicts past results in Nigeria on celebrity endorsement. Also, we found that persuasive communication that considers the cultural factors of the target public is more effective than an advertisement that does not. Therefore, this shows that the little effectiveness of the persuasion is due to the embedded cultural values that are relevant to the target public, rather than a direct effect of the celebrity endorsement dimensions. However, other possible confounding factors may have contributed to the effectiveness of the persuasion. This result of cultural influence on 
communication receivers is in line with previous studies (Biswas Hussain, \& O'Donnell, 2009; Cho et al., 1999; Han \& Shavitt, 1994; G. Hofstede et al., 2010).

Findings on source credibility influence and audience perceptions in this study are markedly different from past studies. The effect of celebrity endorsement is relatively negative to its general assumption in the past studies. This supports scholars who argue that the strategy effectiveness is not automatic (Biswas Hussain, \& O’Donnell, 2009; Reidenbach \& Pitts, 1986) and may be limited to Western society since the African's perceptions according to this study are different significantly from the West. The findings also show that the audience perceived the endorser as not credible, thus not trustworthy because they do not believe the celebrity; this supports previous studies (Biswas et al., 2009; Mick, 1992).

Surprisingly, expertise and attractiveness are perceived contrary to findings from existing studies. Expertise of the endorsers is perceived from their acting domain -professionalismin contrast to the prevalent views in past studies (Petty et al., 1981; Premeaux, 2005) and attractiveness which refers to the beauty and elegance (physical) attribute of a celebrity (Ohanian, 1990; Venkatesakumar, Sathyanarayanan, \& Sathish, 2012; D. Yoon \& Kim, 2016) is perceived as "ability to pull crowd"; in other word, the celebrity's aura of crowd attraction. Though, Erdogan (1999) maintains that attractiveness also includes other none physical characteristics of the celebrity. However, extant studies have always emphasised on attractiveness as a physical attribute of the celebrity. Going by this view, our findings do not support existing results. Nevertheless, perceiving attractiveness as the celebrity's power to pull crowd could be translated in relation to past studies as the ability to generate publicity for the endorsed brand (Biswas Hussain, \& O'Donnell, 2009). Moreover, equating expertise with professionalism could be as a result of using film stars virtually in all the endorsement adverts.

We expected ethnicity to have effect on target public attitudes; meanwhile, it does not unlike other studies (Deshpande \& Stayaan, 1994; Forehand, Deshpandé, \& Reed II, 2002). But it may have partial influence when aligning with other cultural values. And based on the moderator's observation of audience difficulty in recalling the name of a celebrity other than receivers' tribe could imply a partial effect or a mere coincidence. Nevertheless, this is against the theoretical framework that receivers are likely to be more persuaded by their tribespersons based on their social cognitive experiences; and the tribal sentiment that permeates the nook and cranny of the country.

The study has employed a method not previously used - to our utmost knowledgefor celebrity endorsement and have selected as well different participants across tribes in Nigeria to garner down to earth data. This establishes the authenticity and generalization of the findings. Though the small sample size may be regarded as a limitation in addition to other (FGD) disadvantages such as: group thinking conformance of the group; domineering participant in the group; nevertheless, the results of this study are indicative.

A word of caution for advertising managers, marketers and scholars in developing marketing communication strategies in a multicultural society is that celebrity endorsement should be employed with caution to avoid wasting half of the advertiser's expenditure. The attitude of if it works for them, it will work for Nigerian without any solid empirical support makes advertising managers behave like lemmings in using the celebrity strategy; this should be discouraged. Celebrity endorsement should be recommended and used only 
when it warrant itself and supported with a strong empirical evidence to prove its potential effectiveness and to save advertisers' expenditure.

Moreover, cultural perspective is an important influencing factor in communication strategy; this should always be considered in planning celebrity spokesperson in a multicultural society that is sensitive to its culture. Thus, endorsement appeal that aims at diverse audiences should consider utilizing multiple spokespersons for a national brand. Also, ethnicity, though has no correlational effects on receivers' behaviour in this study, should be considered or relegated to the backstage in relation to the environment where the advertisement will be aired.

Noteworthy in the study is the socioeconomic factors of the target audience influence on celebrity endorsement effectiveness. These are evident in multiple referrals of the discussants to the message content of the advertisement that has a reward for them. This is no doubt cast negative effects on the strategy effectiveness because they are looking for a reward-economic power - which they lack as a result of high power distance created by the government of the country. So, we argue in this study that quality of life and standard socioeconomic factors of target audience contribute to enhancing celebrity effectiveness in any given society.

Conclusively, these findings fail to support results of past studies that celebrity endorsement is effective; though may partially validate past results that celebrity endorsement generates more attention/publicity for the endorsed brand; nevertheless it does not translate to the intended aim: the economic value.

This study validates the past studies that celebrity endorsement that consider cultural background of the receivers is more effective than others that do not. Also, this study has proved on the contrary to the supposedly claimed effectiveness of celebrity in Nigeria. The findings should be interpreted with caution and may not extend to high involvement brands. While there is potential opportunity in utilizing celebrity endorsement in Nigeria, a need to streamline the strategy is imperative. Contextualizing the strategy rather than adopting it could improve its effectiveness in Africa as a whole. There is no fault in celebrity endorsement strategy but the application is faulty. We have to understand and follow African perspectives in utilizing it. Therefore, there is an urgent need for further research efforts-qualitative and quantitative, across the nation with the aim of using the qualitative aspect of it as a launching pad for a rigorous quantitative study with a support of sound theoretical framework. Only then can effective celebrity endorsement and economic value be attained and proved.

\section{REFERENCE}

Agbo, A. A., \& Ome, B. (2017). Happiness: meaning and determinants among young adults of the Igbos of Eastern Nigeria. Journal of Happiness Studies, 18(1), 151-175.

Albarracin, D., \& Shavitt, S. (2018). Attitudes and attitude change. Annual Review of Psychology, 69, 299-327.

Albers-Miller, N. D., \& Gelb, B. D. (1996). Business advertising appeals as a mirror of cultural dimensions: A study of eleven countries. Journal of Advertising, 25(4), 57-70.

Ang, I. (1990). Culture and communication: Towards an ethnographic critique of media consumption in the transnational media system. European Journal of Communication, 5(2), 239-260. 
Arnould, E. J., \& Thompson, C. J. (2005). Consumer Culture Theory (CCT): Twenty years of research. Journal of Consumer Research, 31(4), 868-882.

Bargh, J. A. (1982). Attention and automaticity in the processing of self-relevant information. Journal of Personality and Social Psychology, 43(3), 425.

Biswas, S., Hussain, M., \& O’Donnell, K. (2009). Celebrity endorsements in advertisements and consumer perceptions: a cross-cultural study. Journal of Global Marketing, 22(2), 121137. doi:10.1080/08911760902765940

Bower, G. H., \& Gilligan, S. G. (1979). Remembering information related to one's self. Journal of Research in Personality, 13(4), 420-432.

Briley, D., Jr, R. S. W., \& EnL. (2014). A dynamic view of cultural influence: A review. Journal of Consumer Psychology, 24(4), 557-571.

Cantor, N. (1990). From thought to behavior:" Having" and" doing" in the study of personality and cognition. American Psychologist, 45(6), 735-750.

Cho, B., Kwon, U., Gentry, J. W., Jun, S., \& Kropp, F. (1999). Cultural values reflected in theme and execution: A comparative study of US and Korean television commercials. Journal of Advertising, 28(4), 59-73.

Cox, T. H., Lobel, S. A., \& McLeod, P. L. (1991). Effects of ethnic group cultural differences on cooperative and competitive behavior on a group task. The Academy of Management Journal, 34(4), 827-847.

Cross, S. E., Hardin, E. E., \& Gercek-Swing, B. (2011). The what, how, why, andwhere of selfconstrual. Personality and Social Psychology Review, 15(2), 142-179. doi:10.1177/1088868310373752

de Mooij, M., \& Hostede, G. (2010). The Hofstede model applications to global branding and advertising strategy and research. International Journal of Advertising, 29(1), 85-110. doi:10.2501/S026504870920104X

Deliens, T., Deforche, B., De Bourdeaudhuij, I., \& Clarys, P. (2015). Determinants of physical activity and sedentary behaviour in university students: a qualitative study using focus group discussions. BMC Public Health, 15(1), 201.

Deshpande, R., \& Stayaan, D. M. (1994, February). A Tale of Two Cities: Distinctiveness theory and advertising effectiveness. Journal of Marketing Research, XXX1, 57-64.

Dimofte, C. V., Forehand, M. R., \& Deshpandé, R. (2003). Ad schema incongruity as elicitor of ethnic self-awareness and differential advertising response. Journal of Advertising, 32(4), 7-17. doi:10.1080/00913367.2003.10639142

Erdogan, B. Z. (1999). Celebrity Endorsement: A literature review. Journal of Marketing Management, 15(4), 291-314. doi:10.1362/026725799784870379

Falk, E., \& Scholz, C. (2018). Persuasion, influence, and value: Perspectives from communication and social neuroscience. Annual Review of Psychology, 69.

Forehand, M. R., Deshpandé, R., \& Reed II, A. (2002). Identity salience and the influence of differential activation of the social self-schema on advertising response. Journal of Applied Psychology, 87(6), 1086-1099. doi:10.2139/ssrn.345280

Gotlieb, J. B., \& Sarel, D. (1991). Comparative advertising effectiveness: the role of involvement and source credibility. Journal of Advertising, 20(1), 38-45.

Gudykunst, W. B., Matsumoto, Y., Ting-toomey, S., Nishida, T., Kim, K., \& Heyman, S. (1996). The Influence of cultural individualism-collectivism, self construals, and individual 
values on communication styles across cultures. Human Communication Research, 22(4), 510-543. doi:10.1111/j.1468-2958.1996.tb00377.x

Gudykunst, W. B., \& Ting-Toomey, S. (1988). Culture and affective communication. American Behavioral Scientist, 31(3), 384-400.

Han, S., \& Shavitt, S. (1994). Persuasion and culture: Advertising appeals in individualistic andcollectivistic societies. Journal of Experimental Social Psychology, 30, 326-350.

Hofstede, G. (1980). Motivation, leadership, and organization: do American theories apply abroad? Organizational dynamics, 9(1), 42-63.

Hofstede, G., de Hilal, A. V. G., Malvezzi, S., Tanure, B., \& Vinken, H. (2010). Comparing regional cultures within a country: lessons from Brazil. Journal Of Cross-Cultural Psychology, 41(3), 336-352. doi:10.1177/0022022109359696

Kaikati, J. G. (1987). Celebrity advertising. International Journal of Advertising, 6(2), 93-105. doi:10.1080/02650487.1987.11107007

Kamins, M.A. (1990). An investigation into the "match-up" hypothesis in celebrity advertising: When beauty may be only skin deep. Journal of Advertising, 19(1), 4-13.

Kamins, M. A., \& Gupta, K. (1994). Congruence between spokesperson and product type: A matchup hypothesis perspective. Psychology \& Marketing, 11(6), 569-586.

Lalwani, A. K., \& Shavitt, S. (2013). You get what you pay for? Self-construal influences pricequality judgments. Journal of Consumer Research, 40(2), 255-267.

Lewicki, P. (1984). Self-schema and social information processing. Journal of Personality and Social Psychology, 47(6), 1177-1190.

Lodge, M., \& Hamill, R. (1986). A partisan schema for political information processing. American Political Science Review, 80(2), 505-519.

Markus, H. (1977). Self-Schemata and Processing Information About the Self. Journal of Personality and Social Psychology, 35(2), 63-78.

Markus, H., \& Kitayama, S. (1991). Cultural Variation in the Self-Concept. In J. Strauss \& G. R. Goethals (Eds.), The Self: Interdisciplinary approaches (pp. 1-255). New York, NY: Sringer-Verlag. doi:10.1 007/978-1-4684-8264-5

Markus, H. R., \& Kitayama, S. (1991). Culture and the self: Implications for cognition, emotion, and motivation. Psychological Review, 98(2), 224-253.

Martin-Santana, J. D., \& Beerli-Palacio, A. (2013). Magazine advertising: factors influencing the effectiveness of celebrity advertising. Journal of Promotion Management, 19, 139-166. doi:10.1080/10496491.2013.769471

Mick, D. G. (1992). Levels of subjective comprehension in advertising processing and their relations to ad perceptions, attitudes, and memory. Journal of Consumer Research, 18(4), 411-424.

Mick, D. G., \& Buhl, C. (1992). A meaning-based model of advertising experiences. Journal of Consumer Research, 19(3), 317-338.

Mishra, A. S., Roy, S., \& Bailey, A. A. (2015). Exploring brand personality-celebrity endorser personality congruence in celebrity endorsements in the Indian context. Psychology $\mathcal{E}$ Marketing, 32(12), 1158-1174.

Misra, S., \& Beatty, S. E. (1990). Celebrity spokesperson and brand congruence: an assessment of recall and affect. Journal of Business Research, 21, 159-173. 
Morimoto, M., \& Ferle, C. L. (2008). Examining the influence of culture on perceived source credibility of Asian Americans and the Mediating role of similarity. Journal of Current Issues and Research in Advertising, 30(1), 49-60.

Nishida, H. (1999). A cognitive approach to intercultural communication based on schema theory. International Journal of Intercultural Relations, 23(5), 753-777.

Ohanian, R. (1990). Construction and validation of a scale to measure celebrity endorser's perceived expertise, trustworhiness, and attractiveness. Jornal of Advertising, 19(3), 39-52.

Ohanian, R. (1991). The impact of celebrity spokespersons' perceived image on consumers' intention to purchase Journal of Advertising Research(February/March), 46-54.

Petty, R. E., Cacioppo, J. T., \& Goldman, R. (1981). Personal involvement as a determinant of argument-based persuasion. Journal of Personality and Social Psychology, 41(5), 847-855.

Pornpitakpan', C. (2004). The Persuasiveness of Source Credibility: A critical review of five decades' evidence. Journal of Applied Social Psychology, 34(2), 243-228.

Premeaux, S. R. (2005). The attitudes of middle class male and female consumers regarding the effectiveness of celebrity endorsers. Journal of Promotion Management, 11(4), 33-48. doi:10.1300/J057v11n04_04

Reidenbach, R. E., \& Pitts, R. E. (1986). Not all CEOs are created equal as advertising spokespersons: Evaluating the effective CEO spokesperson. Journal of Advertising, 15(1), 30-46.

Rogers, T. B., Kuiper, N. A., \& Kirker, W. S. (1977). Self-reference and the encoding of personal information. Journal of Personality and Social Psychology, 35(9), 677.

Roy, S., Jain, V., \& Rana, P. (2013). The moderating role of consumer personality and source credibility in celebrity endorsements. Asia-Pacific Journal of Business Administration, 5(1), 1757-4323. doi:10.1108/17574321311304549

Scott, L. M. (1994). The bridge from text to mind: Adapting reader-response theory to consumer research. Journal of Consumer Research, 21(3), 461-480.

Silvera, D. H., \& Austad, B. (2004). Factors predicting the effectiveness of celebrity endorsement advertisements. European Journal of Marketing, 38(11/12), 1509-1526.

Singelis, T. M. (1994). The Measurement of Independent and Interdependent Self-Construals. Personality and Social Psychology Bulletin, 20(5), 580-591. doi:10.1177/0146167294205014

Triandis, H. C. (1989). The Self and Social Behavior in Differing Cultural Contexts. Psychological Review, 96, 506-520.

Tzoumakaa, E., Tsiotsoub, R. H., \& Siomkosa, G. (2014). Delineating the role of endorser's perceived qualities and consumer characteristics on celebrity endorsement effectiveness. Journal of Marketing Communication. doi:10.1080/13527266.2014.894931

Venkatesakumar, R., Sathyanarayanan, R., \& Sathish, A. S. (2012). Celebrity endorsementThe North-South divide. Asia-Pacific Journal of Management Research and Innovation, 8(2), 155-163. doi:10.1177/2319510X1200800208

Yoon, D., \& Kim, Y. K. (2016). Effects of self-congruity and source credibility on consumer responses to coffeehouse advertising. Journal of Hospitality Marketing \& Management, 25(2), 167-196. doi:10.1080/19368623.2014.1001932

Yoon, K., Kim, C. H., \& Kim, M.-S. (1998). A cross-cultural comparison of the effects of source credibility on attitudes and behavioral intentions. Mass Communication and Society, 1(34), 153-173. 
Žegarac, V. (2008). Culture and communication. In Helen Spencer-Oatey (Ed.), Culturally speaking: Culture, communication and politeness theory (pp. 48-70). Michigan: Continuum. 